\title{
Bonding strength between bone tissue and implant materials
}

\section{Abstract}

To clarify the bonding strength between bone tissue and implant materials, implant materials were placed in femur bone of beagle dogs and quantitatively measured by a pull-out test using mechanical machine. The bonding strength of HA-coated implants were 2-3MPa at 2 weeks after the placement, 4-6MPa at 4 weeks, 5$10 \mathrm{MPa}$ at 12 weeks, respectively. On the other hand, the bonding strength of titanium or stainless steal implant were less than $1 \mathrm{MPa}$ at 2 weeks and 4 weeks, $1 \mathrm{MPa}$ at 12 weeks, respectively. New bone formation quickly occurred around HA-coated implants after placement in bone compared to titanium, titanium alloy, stainless steal implant. Early cure after placement of implant was expected.

\section{Background and Aim}

\section{Background}

Osseointegration represents a bonding state between bone tissue and titanium or titanium alloy implants in mandible or maxiliary. The bone tissue is closely contact to implants. On bone tissue is closely contact to implants.
the other hand, biointegration is another bonding state of a hydroxyapatite (HA)-coated on titanium implant chemically bonding to bone tissue. However, the bonding strength between bone tissue and implant materials is not clear.

\section{Aim}

The aim of this study is to determine qualitatively the bonding strength between bone tissue and materials by pull-out test. The materials used were pure titanium, SUS316L stainless steal and HA coated titanium by sputtering method and plasma spraying methods. their shape was column without thread. The HA coated columns were made by a plasma spraying, sputtering, thermal decomposition, and dipping methods.

\section{Methods and Materials}

\section{Materials}

The materials used in this study were pure titanium, SUS316L and HA coated titanium and the shapes were columns. The thickness of the coated HA was 0.1 and $1.0 \mu \mathrm{m}$ in sputtering meated HA was 0.1 and $1.0 \mu \mathrm{m}$ in sputtering
method, $1 \sim 3 \mu \mathrm{m}$ in thermal decomposition and method, $1 \sim 3 \mu \mathrm{m}$ in thermal decomposition and
dipping methods, in plasma spraying in $35 \mu \mathrm{m}$. The size was $4 \mathrm{~mm}$ in diameter and $10 \mathrm{~mm}$ in length. The surface was roughened by sandblasting with Ra 1 2 $\mu \mathrm{m}$. The titanium, SUS316L and HA coated titanium columns were implanted in femur bones of beagle dogs. At 2 4, 12 and 24 weeks after the implantation the bonding strength was measured by pull-out test.

Figure 1 shows the column implant materials without thread. The sizes are $10 \mathrm{~mm}$ in length, $4 \mathrm{~mm}$ in diameter.

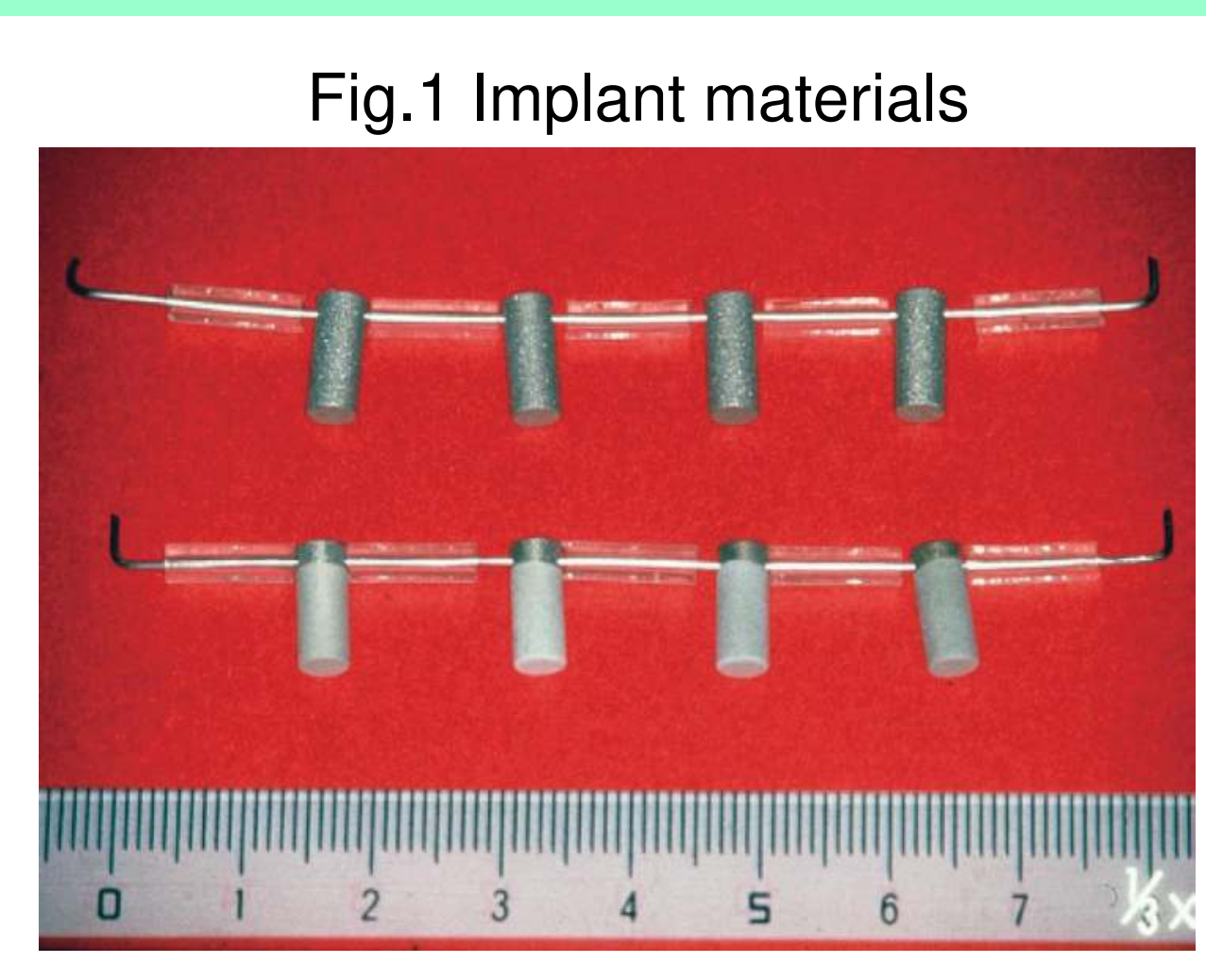

Atsushi Nagaya, Yoshimasa Kitamura, Isho Tsugawa, Tuantuan Li, Hideki Aoki Biointegration Society, Tokyo, Japan

2. Methods

1) Animal test

The column materials were placed in femur bone of beagle dogs. At 2,4, 12, and 24 weeks after the placement, the bone with the columns were extracted

\section{Fig.2 Placment in femur bone}

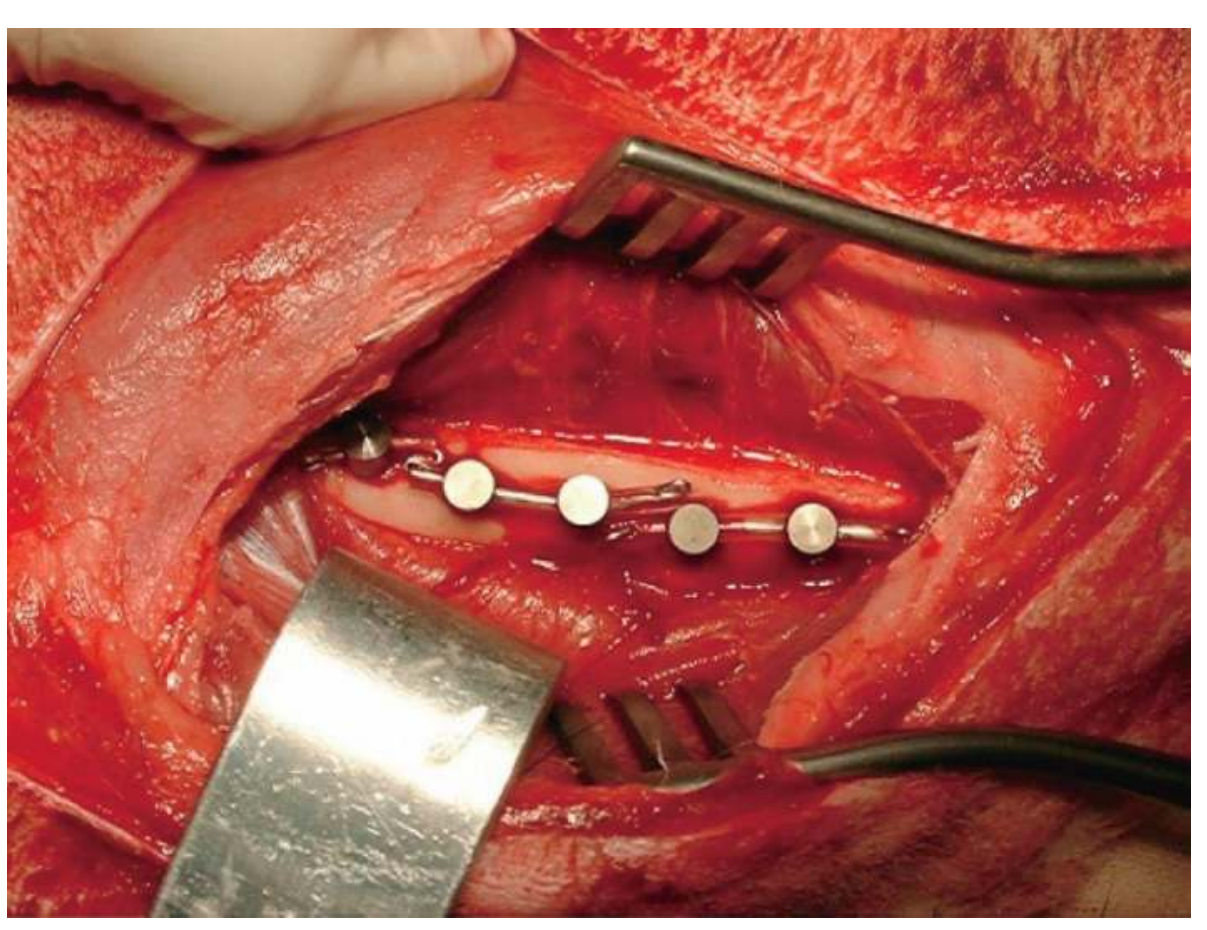

2) Pull-out test

The pull-out test was carried out by a

mechanical machine at a cross head speed of $0.5 \mathrm{~mm} / \mathrm{min}$.

The bone bonding strength was calculated using the following equation.

\section{$\mathrm{P}=\mathrm{F} / \mathrm{TDL}$}

$P$ : Bone bonding strength

F: Pull-out force $(\mathrm{N})$

D: Diameter of column implant

\section{3) Histological observation}

The extracted bone samples with implan materials were fixed, embedded, stained by $\mathrm{HE}$ and cut for histological observation.

\section{Results}

\section{Bonding strength}

At 2 weeks of the implantation the bonding strength of pure titanium and SUS316L columns was less than $0.1 \mathrm{MPa}$. On the other hand, the strength of the HA coated columns made by thermal decomposition and dipping methods were $2 \mathrm{MPa}$ and approximately $3 \mathrm{MPa}$ by sputtering method. At 4 weeks the strength of the pure titanium and SUS316L was approximately $0.1 \mathrm{MPa}$. The strength of the column by sputtering was $6 \mathrm{MPa}$ and by plasma spraying, thermal decomposition, dipping methods were about $4 \mathrm{MPa}$, respectively. At 12 weeks the strength of the column by sputtering weeks the strength of the column by sputtering
method was strongest more than $8 \mathrm{MPa}$. Then, 7MPa by plasma spraying, 5MPa by thermal decomposition and dipping methods. Compared to them the strength of the pure titanium and SUS316L columns were weak approximately $1 \mathrm{Mpa}$. Further, at 24weeks the strength was more than $10 \mathrm{MPa}$ by sputtering, a little lower 7MPa by plasma spraying, $6 \mathrm{MPa}$ by thermal decomposition and dipping methods. The strength of the pure titanium and SUS316L was still $2 \mathrm{MPa}$.

Fig.3 bone bonding strength

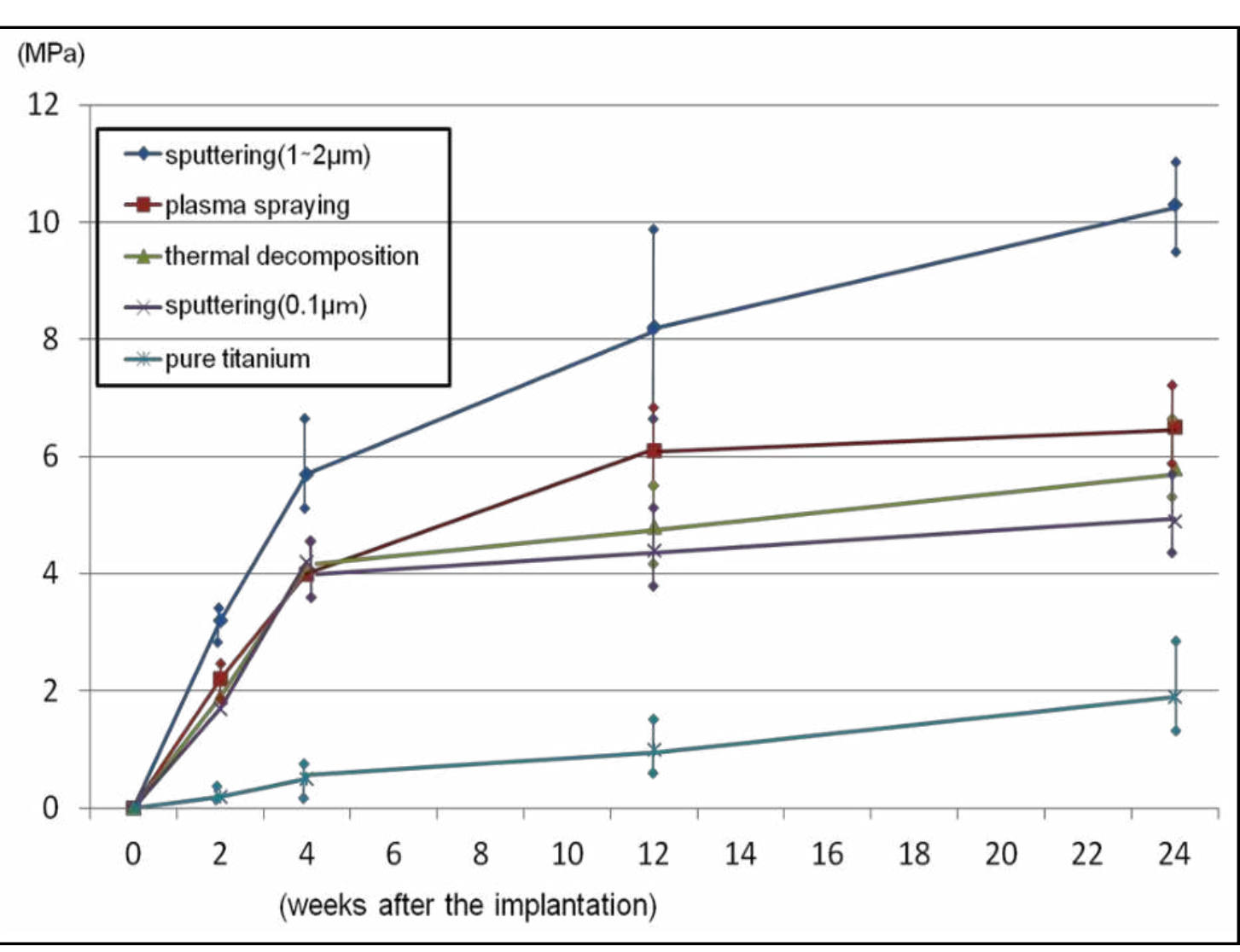

\section{Histological observation}

Fig. 4 shows histological observation at 2 and 4weeks after placement. Control is titanium or SUS316L material and sputtered-coated is HA-coated implant. At early stage of implantation new bone formation will quickly occur around the HA-coated material compared to titanium or SUS316L
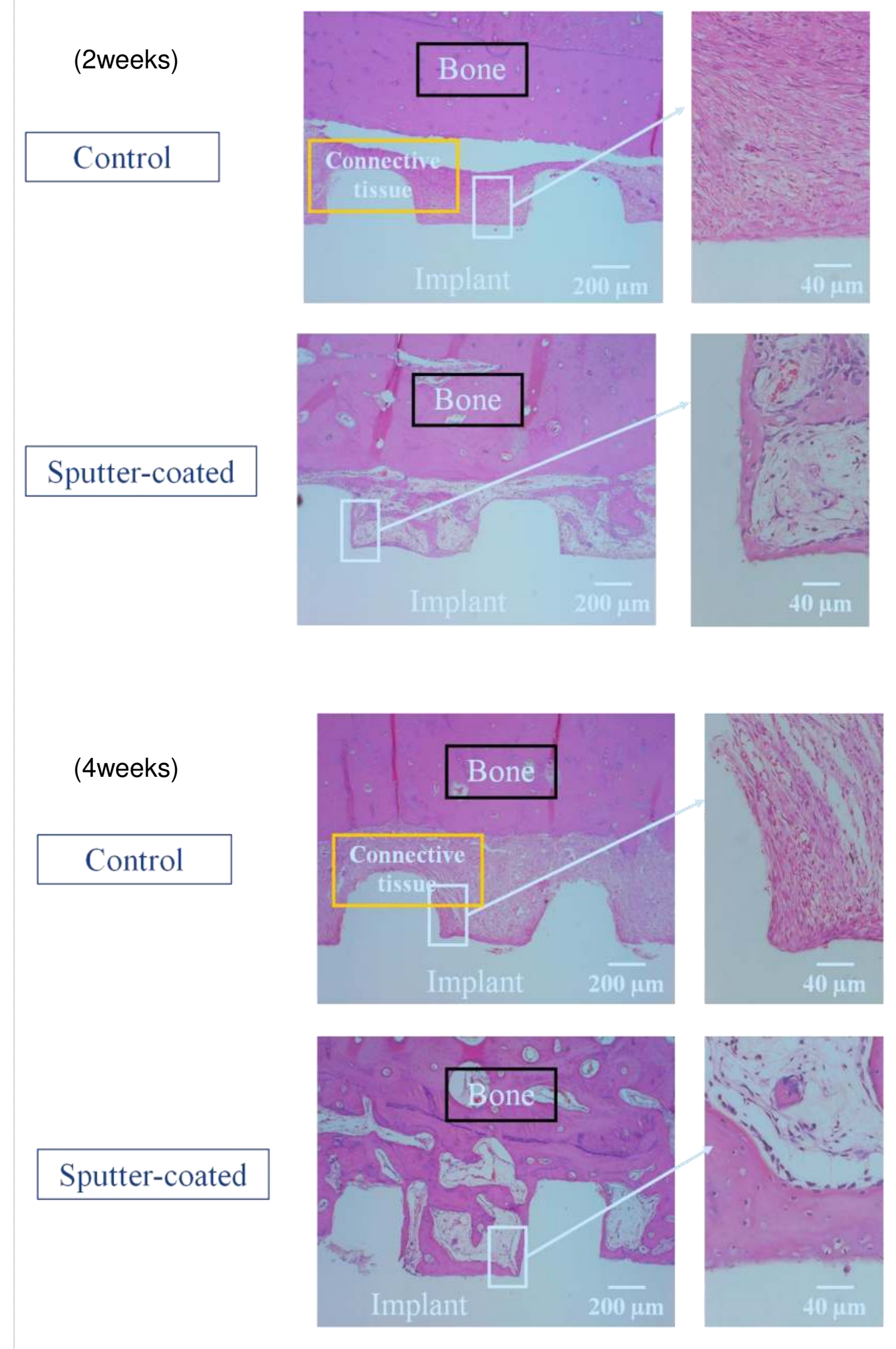

Conclusions

1. At 2 weeks after implantation the bonding strength between bone tissue and $\mathrm{HA}$ coated column materials was 2-4MPa, on the other hand the bonding strength of titanium or SUS316L was less than $0.1 \mathrm{MPa}$. At 4 weeks the bonding strength of $\mathrm{HA}$ coated materials was 4-6MPa and less than $1 \mathrm{MPa}$ in titanium or SUS316LMPa.

2. The strength order was in HA coated materials as follows: sputtering > plasma spraying $=$ thermal decomposition $=$ dipping $>$ pure titanium $=$ SUS316L.

\section{Refferences}

1. P.I.Braunemark et al: Intra-osseous anchorage of dental prosthesis, 1. Experimental studies, J. Plast Reconstr Surg. Vol.3, 81-100, 1969.

2. Yo Ukegawa, et al; Animal study of hydroxyapatite-coated SUS316L by plasma spraying technique, Jpn. Orthopedic Ceramic Implants, Vol.5, 191-195, 1985.

3. Hideki Aoki, Osseointegration and Biointegration, part1 Definition and Mechanism, J. Bio-Integration, Vol.1, 67-74, 2011.

4. Hideki Aoki, Osseointegration and Biointegration, part2 How are different in each integration?, J. Bio-Integration, Vol. 2 157-164, 2012 